\title{
Kommmentar
}

Internist 2020 61:646

https://doi.org/10.1007/s00108-020-00810-3

Online publiziert: 19. Mai 2020

(c) Springer Medizin Verlag GmbH, ein Teil von Springer Nature 2020
M. Augustin - M. Hallek

Klinik I für Innere Medizin, Universitätsklinikum Köln (AöR), Köln, Deutschland

\section{Aktuelles Studienergebnis unterstreicht zurückhaltende Kommentierung}

\section{Kommentar zu}

Augustin M, Hallek M, Nitschmann S (2020)

Remdesivir bei Patienten mit schwerer COVID-

19. Internist. https://doi.org/10.1007/s00108020-00800-5

Die am 29.04.2020 im Lancet erfolgte Publikation einer placebokontrollierten, randomisierten Studie zu Remdesivir bei COVID-19-Patienten [1], die im Ergebnis negativ war, unterstreicht die zurückhaltende Kommentierung der hier vorgestellten Studie.

\section{Korrespondenzadresse}

M. Augustin

Klinik I für Innere Medizin, Universitätsklinikum Köln (AöR)

Kerpener Str. 62, 50937 Köln, Deutschland max.augustin@uk-koeln.de

\section{Literatur}

1. Wang Yetal (2020) Remdesivirinadults with severe COVID-19: a randomised, double-blind, placebocontrolled, multicentre trial. Lancet. https://doi. org/10.1016/S0140-6736(20)31022-9 